\title{
CARDIO-AORTIC FISTULA
}

\author{
BY \\ ALASTAIR MACLEOD \\ From the London Hospital \\ Received September 12, 1944
}

A diastolic murmur heard along the right border of the sternum is regarded as evidence of aortic incompetence, but to this general rule of auscultation there is one exception, and this was present in the case reported here.

A labourer, aged 54, was admitted to the London Hospital with breathlessness and swelling of the legs. He had been quite well until two weeks before admission, when he complained of abdominal pain, vomiting, and great breathlessness. He attributed all his symptoms to indigestion. The pain and vomiting ceased after an hour, but breathlessness recurred on slight exertion. Occasionally effort induced a heavy retrosternal pain which radiated down the right arm. One week before admission he noticed swelling of his ankles. He had a slight cough but there was no sputum. His sleep had been disturbed by attacks of breathlessness. He had never had rheumatic fever nor syphilis; and he had been accustomed to heavy manual work all his life.

On admission he was orthopnœic, but cheerful and cooperative. He was pale and anæmic (hæmoglobin, 56 per cent). The pulse was irregular from auricular fibrillation and rapid (132 a minute). The blood pressure was 115/70. There was venous engorgement in the neck and prominent venous and arterial pulsation. A systolic thrill was felt over the carotid arteries. The apex beat was displaced as far as the anterior axillary line in the sixth intercostal space. The first and second heart sounds were heard over the apex and a third heart sound had been added. A harsh systolic murmur was audible all over the heart, but it was loudest in the aortic area: when the heart rate was slowed to 90 a systolic thrill was felt in the aortic area and a soft diastolic murmur became distinct at the right border of the sternum. This murmur was conducted towards the apex. At the same time the pulse became collapsing in character. There were many crepitations at the lung bases; the liver was distended and ascites was present; and there was pitting œdema of the legs up to the knees. The urine contained a cloud of albumin and the blood urea was $98 \mathrm{mg}$. per 100 c.c. The electrocardiogram showed auricular fibrillation, normal axis deviation, and inversion of the $\mathrm{T}$ waves in leads $\mathrm{I}$ and II. The patient was too ill for cardioscopy to be undertaken. A clinical diagnosis of high blood pressure and heart failure was made, and the aortic diastolic murmur was considered to be the result of relative aortic incompetence. The response to digitalis and mercurial diuretics was poor and the patient died after three weeks in hospital, having developed pyrexia and terminal broncho-pneumonia.

Post-mortem examination (Dr. W. W. Woods). There was great œdema of legs, thighs, and back. In the skin of the upper part of the back, between the shoulders, and the lower part of the back of the neck, there were many confluent dilated veins, more numerous on the right side than on the left. The heart, which weighed $624 \mathrm{~g}$. (22 ounces), showed moderate hypertrophy without dilatation of the left ventricle, slight dilatation of the left auricle, considerable hypertrophy and dilatation of the right ventricle which formed the apex of the heart, and even greater dilatation of the right auricle, particularly of its appendage. In the right auricle, at the junction of the anterior and septal cusps of the tricuspid valve, there was an orifice $(0.7 \mathrm{~cm}$. in diameter). The opening was fimbriated and the irregular fringe projected about $1 \mathrm{~cm}$. above the surface of the valve (Fig. 1). A probe, passed through this opening, appeared at the bottom of the anterior sinus of Valsalva: the opening here was on 


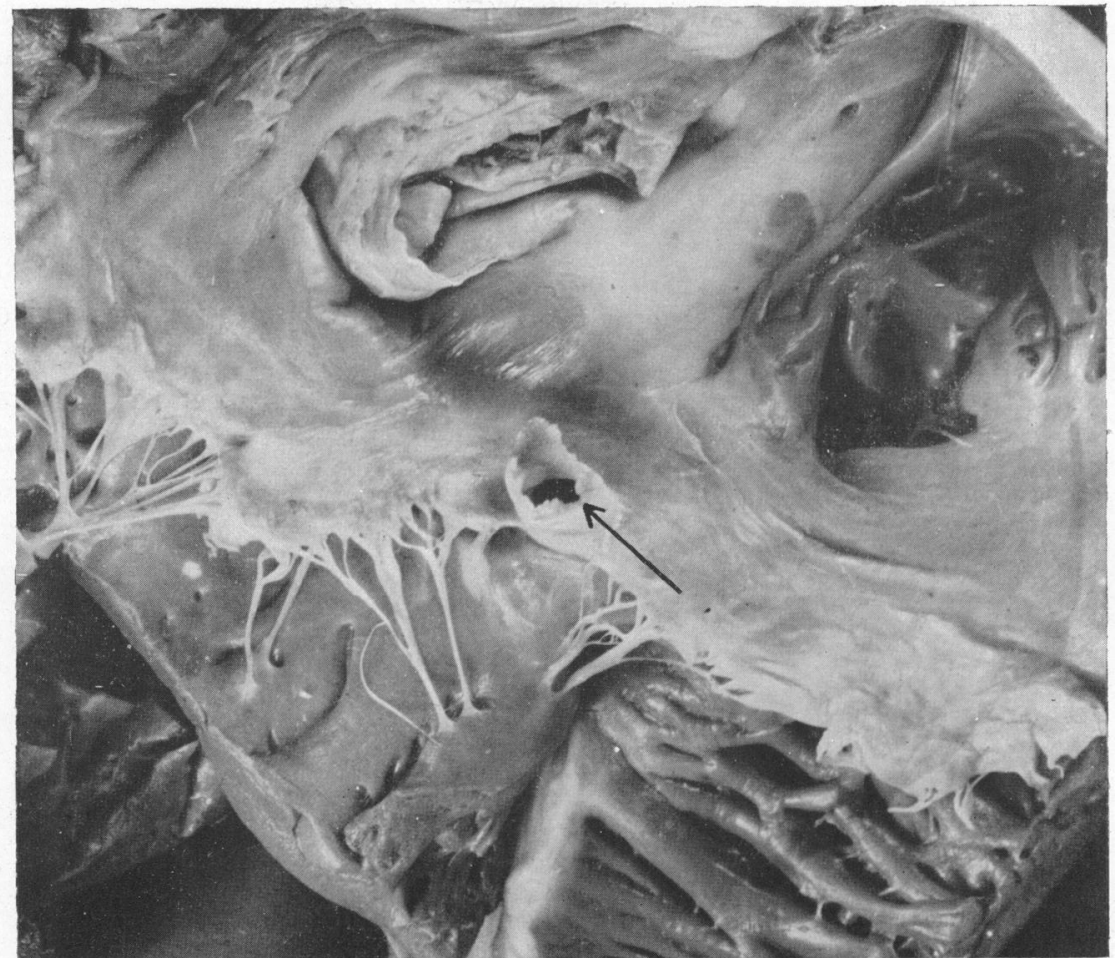

FIG. 1.-Interior of the right auricle. The opening of the cardio-aortic fistula is seen with a fimbriated and irregular fringe projecting about $1 \mathrm{~cm}$. above the surface of the valve. The fimbriated opening (indicated by an arrow) is at the junction of the anterior and septal cusps of the tricusped valve.

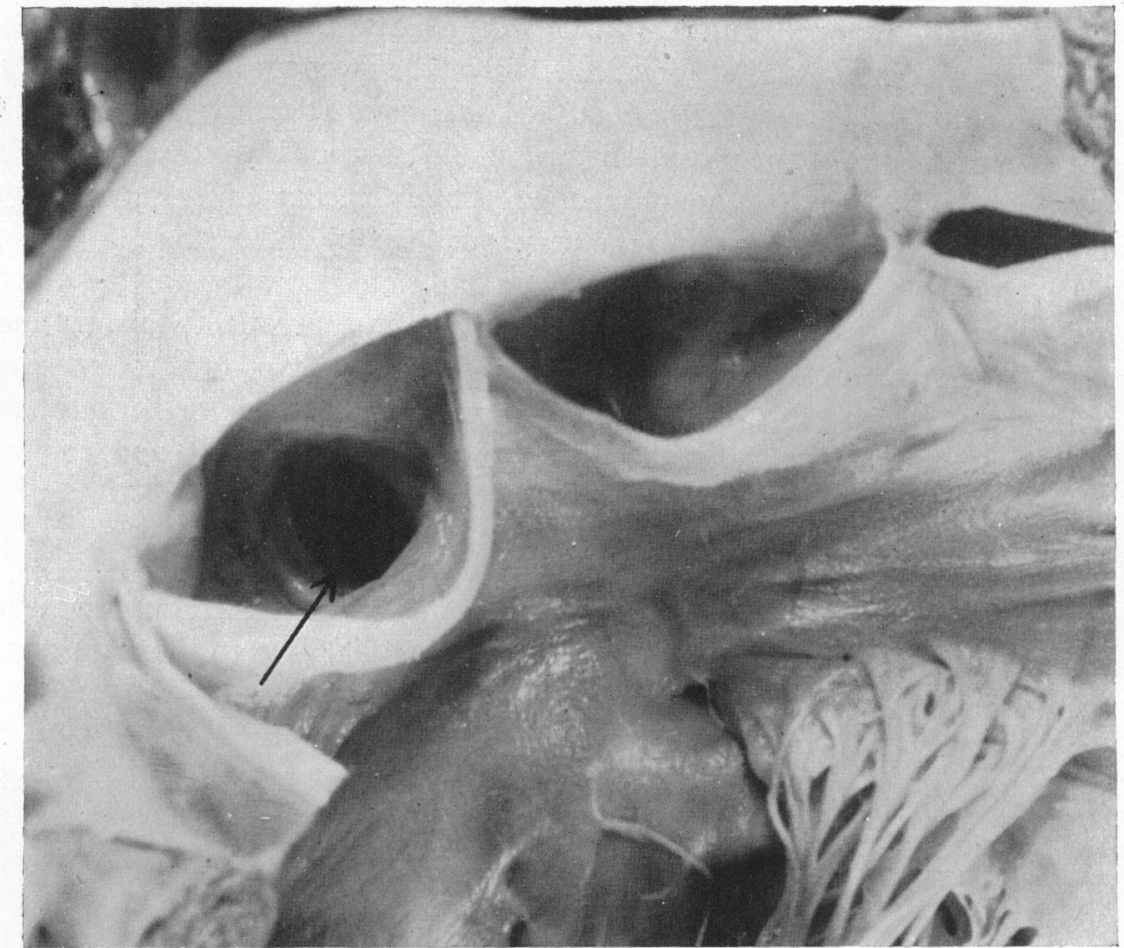

FIG. 2.-The aorta and aortic valves, showing the cardio-aortic fistula (indicated by an arrow) at the bottom of the anterior sinus of Valsalva. 
the left side of the sinus and was $1 \mathrm{~cm}$. in diameter (Fig. 2). The communication between the aorta and auricle was lined by smooth endocardium; there were no vegetations or thickenings. There were no other congenital abnormalities. The aortic valve was competent and measured $8.2 \mathrm{~cm}$. in circumference. The pulmonary valve measured $10.5 \mathrm{~cm}$. in circumference. All valve cusps were normal. Apart from one small button in the anterior descending branch, the coronary arteries were free from atheroma. There was moderate atheroma of the aorta. The pulmonary artery and its branches in the lungs were dilated and there were numerous fat flecks in the larger branches. The lungs showed œdema and congestion, and bronchopneumonic consolidation involved the upper half of the left lower lobe. The right thorax contained 70 c.c. $(2 \cdot 5 \mathrm{oz}$.) of clear fluid and the left contained 42 c.c. $(1 \cdot 5 \mathrm{oz}$.). The abdomen contained 370 c.c. (13 oz.) of clear fluid. The liver was enlarged and showed areas of slight central congestion. The spleen was slightly œdematous and congested. The kidneys were firm from back-pressure congestion; there was no marked fibrosis, but the arcuate arteries were slightly thickened. The changes at necropsy were consistent with hypertensive heart failure and the effects of the cardio-aortic fistula.

\section{Discussion}

Localized defects of the aortic septum may lead to abnormal communication between the base of the aorta and the pulmonary artery or the pulmonary conus. When the opening is from the aorta to the right ventricle or right auricle it usually results from the rupture of a congenital aneurysm of one of the sinuses of Valsalva. Such an aneurysm arising from the posterior sinus of Valsalva and projecting into the right auricle and rupturing there a few hours before death was described by Goehring (1920). He reviewed five similar cases that had been reported; in only one case did an aneurysm from the anterior sinus lead into the right auricle. Abbott (1919) described a case in which an aneurysm of the right sinus of Valsalva had ruptured into the pulmonary conus. A correct clinical diagnosis was made in this case in which a continuous roaring murmur was heard; its accompanying vibration was so marked that it shook the bedclothes. In Goehring's case a loud rough diastolic murmur was heard in the third intercostal space to the left of the sternum and there was a systolic murmur also. Sudden collapse of the patient six hours before death was presumed to correspond with the rupture of the aneurysm. Brown (1939) mentions two cases of sudden death in young people resulting from rupture of an aneurysm of the sinus of Valsalva, into the right auricle and ventricle in one case and into the pericardial cavity in the other.

In the case reported here it is probable that the fimbriated opening was the outcome of a ruptured congenital aneurysm, but there was no episode in the patient's history that would indicate when the rupture took place. The fistula satisfactorily explained the presence of the diastolic murmur and the prominent venous congestion. The case is of further interest because of the age the patient had attained without incurring the most serious and common complication of such congenital lesions-bacterial endocarditis.

SUMMARY

An unusual case is recorded of an elderly man who showed at necropsy a cardio-aortic fistula, which led from the bottom of the anterior sinus of Valsalva to the right auricle near the tricuspid valve.

This communication illustrates a rare cause of a diastolic murmur heard along the right border of the sternum.

I would like to thank Dr. Horace Evans for permission to publish this case, Dr. William Evans for his help and advice, and Mr. John King for the photographs.

\section{REFERENCES}

Abbott, M. E. (1919). Contributions to Medical and Biological Research, New York, 2, 899.

Brown, J. W. (1939). Congenital Heart Disease, London.

Goehring, C. (1920). J. Med. Research, 42, 49. 